\title{
Intergroup Contact and Endorsement of Social Change Motivations: The Mediating \\ Role of Intergroup Trust, Perspective-Taking, and Intergroup Anxiety among Three Advantaged Groups in northern Cyprus, Romania, and Israel
}

\author{
Huseyin Cakal ${ }^{1}$ \\ Samer Halabi ${ }^{2}$ \\ Ana-Maria Cazan ${ }^{3}$ \\ Anja Eller 4 \\ Submitted for publication in Group Processes and Intergroup Relations \\ An updated version of this manuscript is available from the journal's website.
}

1: School of Psychology, Keele University, UK

2: The Academic College of Tel Aviv-Yaffo, Israel

3: Transilvania University of Brasov, Romania

4: Universidad Nacional Autónoma de México, Mexico

Address correspondence to: Huseyin Cakal, School of Psychology, Dorothy Hodgkin Building, Keele University, Keele, Staffordshire, ST5 5BG

U.K.

Electronic mail: $\underline{\text { h.cakal@keele.ac.uk }}$ 


\begin{abstract}
Three studies investigated the effect of intergroup contact and social identification on social change among the three advantaged groups in Cyprus, Romania, and Israel. In Study 1 ( $n=340$, Turkish Cypriots), intergroup contact with the disadvantaged Turks positively predicted endorsement of social change motivations by disadvantaged Turkish immigrants, directly, and via intergroup trust and perspective-taking. In Study 2 ( $n=200$, Romanians), contact with the ethnic minority Hungarians positively predicted endorsement of social change motivations by the Hungarians via intergroup trust, perspective-taking, and intergroup anxiety, and in-group identification negatively predicted endorsement of collective action tendencies by the Hungarian ethnic minority, via perspective taking and anxiety only. In Study 3 (n=240, Israeli Jews), intergroup contact positively and in-group identification negatively predicted endorsement of social change motivations by the disadvantaged Palestinian citizens of Israel via perspective-taking, anxiety, and trust. Across three studies, results show that intergroup contact led the advantaged group to attitudinally support social change motivations of the disadvantaged outgroups through increased trust and perspective-taking, and reduced anxiety whereas in-group identification weakened their motivation to support social change motivations via perspective-taking and intergroup anxiety in Study 2, and via intergroup trust, perspective-taking, and intergroup anxiety in Study 3.
\end{abstract}




\section{Introduction}

Most research on social change shows that disadvantaged individuals engage in social change attempts to redress the incidental or structural inequalities, e.g. imbalance in terms of social, economic, or political power against their group (Haferkamp \& Smelser, 1992) when they perceive that they are being disadvantaged on the basis of their membership to that group when they are angry about this disadvantage, and when they perceive themselves to be capable of redressing this disadvantage collectively (van Zomeren, Postmes, \& Spears, 2008). Research has also shown that, among the members of the disadvantaged groups, positive interactions with members of advantaged groups can mitigate these processes by improving attitudes toward the advantaged group and decreasing intentions to engage in collective action, a process known as the so called sedative effect of contact (Cakal, Hewstone, Guler, \& Heath, 2016; Cakal, Hewstone, Schwar, \& Heath, 2011; Dixon, Tropp, Durrheim, \& Tredoux, 2010; Saguy, Tausch, Dovidio, \& Pratto, 2009). However, much less is known on the psychological conditions that promote or hinder support for social change benefitting the disadvantaged among the members of the advantaged groups.

This is surprising as changing the structures that create and perpetuate the disadvantage also depends on how much the advantaged group is prepared to defend the status quo or how willing it is to support the social change attempts by the disadvantaged outgroup (Pettigrew, 2010). Psychological mechanism such as positive interactions that are known to hinder social change attempts among the disadvantaged groups might actually energize social change among the advantaged groups. Here, we focus on vertical interactions, intergroup contact between advantaged and disadvantaged groups, and investigate the potential effects of contact (Allport, 1954; Pettigrew, 1998) on endorsement of social change motivations of the disadvantaged among the advantaged groups. 
Emerging research shows that intergroup contact between disadvantaged groups as well as contact between advantaged and disadvantaged groups might have positive effects on social change. In fact, as an effective prejudice reduction strategy, contact has the potential to instigate processes that might encourage social change motivations in several ways. First, contact may enhance social change via fostering solidarity and empowerment, horizontally, between disadvantaged groups (Cakal, Eller, Sirlopú, \& Perez, 2016; Dixon et al., 2017), or vertically, between advantaged and disadvantaged groups (Reimer et al., 2017; Selvanathan, Techakesari, Tropp, \& Barlow, 2018). Second, contact can also encourage the members of the advantaged group to be more inclusive toward the disadvantaged group and to adapt a more critical approach to the in-group's code of conduct toward the disadvantaged outgroup (Pettigrew, 1998; Verkuyten, Thijs, \& Bekhuis, 2010). Thus, by adapting a more inclusive and less critical approach toward the disadvantaged out-group, members of the advantaged group might come to acknowledge the plight of the disadvantaged group and recognize the unfairness of the situation.

Although crucial for social change, this recognition of the illegitimacy of the situation and endorsement of the disadvantaged group's right to challenge this illegitimacy may not always translate into direct action, e.g., petitions, marches, and or protests, to support the rights of the disadvantaged out-group. In some contexts, for instance, where the intergroup division is more pronounced and intergroup relations are conflictual, e.g., Jews and Palestinians in Israel or Romanians and Hungarians in Romania, members of the advantaged group may refrain from engaging in collective action in favour of the disadvantaged outgroup but they might be still motivated to support disadvantaged group's rights via alternative ways such as attitudinal support for policies benefitting the disadvantaged (Dixon, Durrheim, et al., 2010), donating money and time for the advancement of the disadvantaged 
outgroup's rights (Fingerhut, 2011), or supporting the disadvantaged groups' collective action.

Last but not least, contact can also indirectly energize social change efforts among the advantaged via its sedative effect by reducing collective action intentions aimed at maintaining the status quo among the advantaged group members directly (Study 2, Cakal, Hewstone, Schwar, \& Heath, 2011) or indirectly by reducing perceptions of in-group efficacy and perceived threats from the out-group (Study 2, Cakal, Hewstone, Schwar, \& Heath, 2011 and Study1, Çakal, Hewstone, Güler, \& Heath, 2016, respectively).

In the present research, we turn our gaze to intergroup trust, perspective-taking, and intergroup anxiety as potential affective processes (Swart, Hewstone, Christ, \& Voci, 2011) through which intergroup contact a) might lead to an endorsement of the disadvantaged group's right to challenge the illegitimate and unfair conditions; b) might exert its sedative effect on counter -collective action intentions among the advantaged in-group.

Below, we first provide an outline of research on how contact and identification with the in-group influence trust, perspective taking, and anxiety in intergroup encounters. We then integrate this research with research on social change by proposing that, among the members of the advantaged groups, trust and perspective-taking can increase willingness to endorse disadvantaged groups' attempts to challenge the illegitimate status quo while effectively decreasing willingness to engage in in-group serving collective action. We also argue that, anxiety might be simultaneously associated with less willingness to endorse social change efforts in favour of the disadvantaged out-group and stronger motivations to engage in collective action in favour of the advantaged in-group. We expect the very same mechanisms, i.e. social identity, that induce endorsement of social change attempts by the disadvantaged to have a negative effect on social change motivations among the advantaged in-group. In particular, we surmise that identification with the advantaged in-group could 
decrease attitudinal support for social change attempts by the disadvantaged out-group and increase motivations to engage in collective action for the advantaged in-group via decreased trust and perspective taking, and via increased anxiety.

\section{Intergroup Trust, Perspective-Taking, and Intergroup Anxiety}

Meta-analytic research by Pettigrew and Tropp (2008) shows that one possible mechanism through which contact improves intergroup attitudes is via affective processes, by increasing trust and perspective-taking, and decreasing intergroup anxiety. In the present research we operationalize intergroup trust as expectations that out-group members will cooperate with in-group members and will not take advantage of them (Lewicki, McAllister, \& Bies, 1998), and perspective-taking as cognitively oriented emphatic concern aimed at understanding others' thoughts and viewing the world from others' viewpoint (Davis, 2004; Galinsky, Ku, \& Wang, 2005). Last but not least, we define intergroup anxiety as an apprehension experienced in anticipation of or during intergroup interaction with the members of the outgroup (Stephan, 2014; Stephan \& Stephan, 1985).

\section{Intergroup Trust}

Trust is an iterative process that builds upon prior successful interactions and has the capacity to promote a positive approach and reconciliatory acts toward the out-group (Tam, Hewstone, Kenworthy, \& Cairns, 2009). Because trust creates an anticipation of others' benevolent intentions when groups are involved in a conflict, it holds a great promise for reconciliation and compromise in times of turmoil. Conflicts make group identities more salient, and salient identities are associated with in-group favouritism, increased perception of threats, and (dis)trust (Brown, 2000; Cehajic, Brown, \& Castano, 2008). Once established, trust can motivate individuals to work together toward common goals with members of the rival group (Kramer \& Carnevale, 2001; Tam et al., 2009) and renounce their privileges toward this cooperation (Tanis \& Postmes, 2005). Because building trust relies on positive interactions 
and is negatively influenced by salient group identities, trust could plausibly mediate the effects of intergroup contact and in-group identification on in-group collective action intentions and endorsement of social change motivations among the disadvantaged out-group. On one hand, positive contact could predict increased intergroup trust and trust in turn could predict more support for social change benefitting the disadvantaged out-group. On the other hand, trusting the members of the disadvantaged group more in that they will not exploit the in-group's vulnerabilities during the process could also reduce the advantaged group's willingness to engage in collective action to maintain their group's privileged position.

Despite this preliminary evidence on the positive role of intergroup trust in conflictual settings (Balliet \& Van Lange, 2013), only one study has explored the positive effect of intergroup trust on support for social change. Brylka, Mähönen, Schellhaas, and JasinskajaLahti (2015) investigated the relationship between perceived cultural discordance between the two groups on the cultural rights of the disadvantaged group and collective action via intergroup trust and anxiety among advantaged Finns and disadvantaged Russians in Finland. Among the advantaged Finns, cultural discordance was associated with decreased intergroup trust, which, in turn, predicted less support for collective action by the Russian disadvantaged group.

As interesting as this finding might be, it does not show a) how intergroup trust emerges, b) whether group boundaries play any role in determining the levels of intergroup trust, and c) how intergroup trust influences advantaged group members' willingness to engage in counter collective action aimed at maintaining the status quo.

\section{Perspective-Taking}

Similar to its effects on trust, intergroup contact also has a positive effect on perspectivetaking (Aberson \& Haag, 2007b; Pettigrew \& Tropp, 2008), and a stronger identification with the in-group reduces people's tendencies to see the world from another group's perspective 
(Tarrant, Calitri, \& Weston, 2012). Active consideration of out-group members' experiences of the intergroup environment, i.e., perspective-taking, improves intergroup relations in more than one way (Batson, 2011; Todd \& Simpson, 2017). Firstly, taking the perspective of the out-group positively changes our evaluations of them across a variety of intergroup settings (Batson, Chang, Orr, \& Rowland, 2002; Shih, Wang, Trahan Bucher, \& Stotzer, 2009; Vescio, Sechrist, \& Paolucci, 2003). Secondly, the more we take the perspective of the outgroup the more ready we are to recognize our discrimination against them (Todd, Bodenhausen, \& Galinsky, 2012) and the less in-group favouritism we display (Galinsky \& Moskowitz, 2000), - a key dimension of opposition to social change benefitting the disadvantaged out-group - (Leach, Iyer, \& Pedersen, 2007; Lowery, Unzueta, Knowles, \& Goff, 2006; O'Brien, Garcia, Crandall, \& Kordys, 2010) -. Thirdly, taking the perspective of the disadvantaged out-groupers motivates the members of the advantaged groups to adopt approach-oriented action tendencies toward them (Todd, Hanko, Galinsky, \& Mussweiler, 2011).

As previous research suggests perspective taking could predict collective action one behalf of the disadvantaged outgroup (Mallett, Huntsinger, Sinclair, \& Swim, 2008), and mediate the effects of positive intergroup contact on collective action oriented toward improving the conditions for the disadvantaged outgroup (Fingerhut, 2011; Selvanathan et al., 2018). In the present research, we contend that the effect of perspective taking is not limited to garnering attitudinal support for disadvantaged group's social change attempts and argue that perspective taking can also energize social change by demotivating advantaged group members from taking action to protect their privileges.

Thus, we expect perspective-taking to influence social change attempts by increasing support for social change benefitting the out-group and by decreasing willingness to engage 
in collective action aimed at improving or maintaining the advantaged in-group's position and the status quo.

\section{Inter-group Anxiety}

Much like intergroup trust and perspective taking, intergroup anxiety, too, is influenced by a positive intergroup environment and in-group identification. Contact is associated with reduced intergroup anxiety (Islam \& Hewstone, 1993) while stronger identification with the in-group negatively correlates with increased intergroup anxiety (Stephan, 2014). In turn, intergroup anxiety is positively associated with negative attitudes and negative stereotypes of the out-group (Eller, Abrams, \& Zimmermann, 2011; Islam \& Hewstone, 1993; Renfro, Duran, Stephan, \& Clason, 2006; Swart et al., 2011; Van Zomeren, Fischer, \& Spears, 2007), negative emotions toward the out-group (Binder et al., 2009; Butz \& Plant, 2006), and negative behavioural intentions toward out-groups (van Zomeren et al., 2007). Last but not least, experiencing intergroup anxiety is also negatively associated with positive action tendencies toward out-groups (Costello \& Hodson, 2011; Martinez, 2000).

Scarce research suggests that intergroup anxiety might be associated with decreased support for disadvantaged out-group's political rights (Sengupta \& Sibley, 2013) and mediate the effect of intergroup disagreement on cultural rights of the disadvantaged on willingness to engage in solidarity-based collective action in favour of the disadvantaged out-group (Brylka et al., 2015). Based on these findings, we hypothesize that the negative effects of intergroup anxiety could also stall social change via another route, that is, by increasing willingness to engage in collective action among the advantaged.

In sum, we argue that all three affective processes of trust, perspective-taking, and anxiety, could energize and stall social change attempts among the advantaged groups via a dual pathway by mediating the positive effects of intergroup contact and negative effects of in-group identification on attitudinal support for social change attempts and in-group 
collective action intentions among members of the advantaged group. We test this dual pathway model among three advantaged groups: economically and socially advantaged Turkish Cypriots in Cyprus, majority Romanians in Romania, and Israeli Jews in Israel.

\section{Overview of Present Research Context and Hypotheses}

In our first study, we focused on Turkish Cypriots who have had non-violent conflictual relations with the Turkish immigrants, also known as settlers, who first arrived in the island after the war in 1974. Although exact numbers and demographics of the Turkish immigrants are hard to come by due to an unofficial veil of secrecy imposed by the Turkish Cypriot officials (Loizides, 2011), the last official census conducted in northern Cyprus (2011) puts the overall population of northern Cyprus to 290,000 and the percentage of individuals from Turkey is estimated to be $35 \%$ of the overall population. A great majority of the immigrants have lower levels of education and socioeconomic status and are largely excluded from the political structures and grossly underrepresented in the parliament (Hatay, 2007).

One would expect that both communities have Turkish origins and thus are ethnically similar. However, they are divided along cultural, social, and political fault lines and the group boundaries are salient (Psaltis, Cakal, Kuşçu, \& Loizides, 2019). Recent research shows that almost $50 \%$ of the Turkish Cypriots now consider themselves as Cypriots and perceive their "Cypriotness" as being threatened by the Turks, both at the group and state level (Cakal, 2012; Navaro-Yashin, 2006).

In our second study, we explored the same processes among Romanians in Transylvania-Romania, which is home to a large ethnic minority Hungarians.Romania's last census in 2011 revealed that $1,227,623$ people, or $6.1 \%$ of the total population are Hungarians, making them the largest ethnic minority in Romania. Despite Hungarians making up a small percentage of the total population, there are some Romanian counties in the region of Transylvania, such as Harghita or Covasna, where Hungarians represent more 
than $70 \%$ of the total population. Although the present intergroup context can be best described as non-violent conflictual, the two communities have been involved in violent interethnic clashes as late as 1991 (Culic, Horvath, \& Marius-Magyari, 1998; Lipcsey, Gherman, \& Severin, 2006).

Our third study was conducted in Israel which is home to a sizeable ethnic minority Palestinians. The intergroup context between the groups is often of antagonistic and suspicious nature. According to the official figures, Palestinians constitute $21 \%$ of the overall Israeli population (approaching 9 million; Central Bureue of Statistics, 2016) but they are severally disadvantaged in all domains of public and private rights (Adalah, 2011). The existing power and status discrepancies facilitate increased conflict-supporting beliefs, contribute to mutual stereotyping, enhanced distrust, suspicion, and skepticism in the intentions and motivation of each group's behavior (Hameiri \& Nadler, 2017).

\section{Hypotheses}

We conducted our studies against this backdrop in various intergroup contexts and each with varying degrees of conflict. Our aim was to build on the existing research on the positive effects of intergroup contact on affective mediators, intergroup trust, perspective taking, and intergroup anxiety, and expand this research to provide novel insights into psychological processes that contribute to social change.

More specifically, we hypothesized that:

H1: More contact with the disadvantaged out-group will be associated with more endorsement of the social change motivations by the disadvantaged out-group via increased intergroup trust and perspective-taking, and decreased intergroup anxiety.

H2: Stronger in-group identification will be associated with less support for endorsement of the social change motivations by the disadvantaged out-group via decreased intergroup trust and perspective-taking, and increased intergroup anxiety. 
H3: More contact with the disadvantaged out-group will be associated with less support for the collective action for the advantaged in-group via increased intergroup trust and perspective-taking, and via decreased intergroup anxiety.

H4: Stronger in-group identification will be associated with more support for the collective action for the advantaged in-group via decreased intergroup trust and perspectivetaking, and increased intergroup anxiety.

We tested these hypotheses in the three studies we report below. Across all three studies, we employed the same base questionnaire which was translated to and back translated from Turkish, Romanian, and Hebrew by qualified translators for equivalence. Whenever possible we used the same items to build our models except in Study 2 in which we had to measure support for out-group collective action with two items only to improve the reliability of our measure.

\section{Study 1}

\section{Method}

Participants. We recruited $336(143$ females, Mage $=37.55$ and $S D=11.12)$ adult participants online who self-identified as Turkish Cypriots. The first author contacted the participants via social media and invited them to participate in a survey on the current political issues in northern Cyprus. After consenting, participants were emailed the link to the survey. Any information that might help to identify the participants was removed before the analysis.

Measures. We measured all variables by multi-item 7-point Likert-type scales in which higher values (e.g., 1 = strongly disagree; 7 = strongly agree) indicate higher levels of the respective variable.

We measured intergroup contact with three items $(\alpha=.90)$ : 'How often do you interact with your Turkish friends?', How often do you participate in the special days 
(birthday, funeral, and other similar occasions) of your Turkish friends/their family?', 'How often do your Turkish friends participate in your/your family's special days (birthday, funeral and other similar occasions)?'. Hence, our contact measure was a combination of quantitative (frequency of interactions) and qualitative (friendship) aspects which should be most effective for reducing prejudice and improving intergroup relations.

In-group Identification as Turkish Cypriot was measured by three items $(\alpha=.81)$, adapted from Luhtanen and Crocker (1992): 'Being Turkish Cypriot is an important part of my identity', 'I am very happy to be a Turkish Cypriot', 'I am very proud to be a Turkish Cypriot'.

Inter-group trust was measured by three items $(\alpha=.71)$ derived from Brown, Cehajic, and Castano (2008) and Tam, Hewstone, Kenworthy, and Cairns (2009): 'Most members of the Turkish immigrant community in Cyprus can be trusted', 'Despite everything, I trust Turkish immigrants', ‘Turkish Cypriots can trust Turkish immigrants in Cyprus'.

Perspective-taking was measured by three items $(\alpha=.84)$, adapted from Batson et al. (1997): 'I can see things from the point of view of Turkish immigrants'; 'I don't waste my time listening to the arguments of Turkish immigrants' (reverse coded), and 'On most issues, I am able to grasp the perspective of Turkish immigrants'.

Intergroup anxiety was measured by three items $(\alpha=.79 ;$ Stephan \& Stephan, 1985). Participants reported how likely they were to feel 'apprehensive, uncertain, careful,' when interacting with members of the Turkish immigrant out-group.

Collective Action for the Turkish Cypriot in-group was measured by three items $(\alpha=$ .94), adapted from Smith, Cronin, and Kessler (2008): 'I would vote for a candidate who would improve the current situation of Turkish Cypriots in northern Cyprus', 'I would be willing to become a member of an organization that supports Turkish Cypriot rights in 
northern Cyprus', 'I would be willing to sign a petition to improve the current situation of Turkish Cypriots in northern Cyprus'.

We adapted the same three items $(\alpha=.83)$ to measure endorsement of social change attempts by the out-group: 'Turkish immigrants are right to vote for a candidate who would improve the current situation of Turkish immigrants in Cyprus', 'Turkish immigrants are right to become a member of an organization that supports Turkish immigrants' rights in Cyprus', 'Turkish immigrants are right to sign a petition to improve the current situation of Turkish immigrants in Cyprus'.

\section{Results and Discussion}

Model construction. We used a structural equation modelling approach to test our model in Mplus 8 (Muthen \& Muthen, 2008b, 2008a). We first ran a confirmatory factor analysis to check the construct validity of our scales. As we expected, our observed variables had good loadings on to their respective latent variables (above .50; Kline, 2011). Our model demonstrated an excellent fit to the data $\left(\chi^{2}=190.06, p=.088, d f=165, \mathrm{CFI}=.99\right.$, RMSEA $=.021, \mathrm{SRMR}=.031$; good fit is indicated by non-significant $\chi^{2} ; .06$ or lower for RMSEA; .95 or higher for CFI; and .08 or lower for SRMR; see Bentler, 2007; Hu \& Bentler, 1999).

Hypothesis testing. The descriptive statistics and zero-order correlations between our latent variables in the model are reported in Table 1.

\section{[Table 1]}

Our model (Figure 1) explained $23 \%$ and $17 \%$ of variance in endorsement social change attempts by the Turkish out-group and Turkish Cypriot in-group collective action, respectively. In addition, the model accounted for $32 \%$ of the variance in intergroup trust, $8 \%$ of the variance in perspective-taking, and $25 \%$ of the variance in intergroup anxiety.

[Figure 1] 
Contact positively predicted endorsement of collective action by the Turkish outgroup directly $(\beta=.16, p<.05)$ and via intergroup trust $(\mathrm{PE}=.12,95 \% \mathrm{CIs}[.006, .255])$; and perspective-taking $(\mathrm{PE}=.07,99 \% \mathrm{CIs}[.016, .144])$; Contrary to our expectations, in-group identification as Turkish Cypriot was positively associated $(\beta=.36, p<.001)$ with intentions to engage in collective action for the Turkish Cypriot in-group only. These results provided only partial support to our hypotheses ${ }^{1}$.

Discussion. Results partially supported the positive effects of contact on social change directly and via increased intergroup trust and perspective taking only. To the extent that Turkish Cypriots had more contact with the disadvantaged Turkish immigrants they trusted the out-group more and they took the perspective of the Turkish immigrants more. In turn, both intergroup trust and perspective-taking were associated with stronger endorsement of the social change attempts by the disadvantaged Turkish out-group. We found a direct positive association between in-group identification as Turkish Cypriot and collective action tendencies in favour of the in-group but there was no evidence of the negative indirect effects of in-group identification on social change via trust, perspective taking or anxiety. This evidence shows that contact increases attitudinal support for social change benefitting the disadvantaged outgroup by increasing trust and perspective taking and it is not related to in-group collective action at least among the Turkish Cypriots. We sought to replicate these findings in a more conflictual setting, in the context of Romanian-Hungarian intergroup relations in Romania.

\section{Study 2}

\section{Method}

Participants. $197(125$ females, Mage $=20.75$ and $S D=3.92)$ participants studying at a university in Transylvania-Romania were recruited on a voluntary basis by a Romanian research assistant to participate in a survey on the political issues in Transylvania. After agreeing, all participants completed a paper and pencil questionnaire. 
Measures. We used the same items as in Study 1 to measure our variables, but had to adjust the scale measuring endorsement of out-group's social change motivations. The reliability value for the initial three-item scale was below the accepted threshold $(\alpha=.53)$ so we dropped the item 'Hungarians are right to vote for a candidate who would improve the current situation of Hungarians in Transylvania-Romania' and used the remaining two items ( $\mathrm{r}$ $=.78, \mathrm{p}<.001)$. All the other measures demonstrated good to excellent reliability (intergroup contact $\alpha=.81 ;$ in-group identification as Romanian $\alpha=.89$; intergroup trust $\alpha=.86$; perspective taking $\alpha=.79$; anxiety $\alpha=.82$; collective action for the Romanian in-group $\alpha=$ .77).

\section{Results and Discussion}

Model construction. As in Study 1, we tested our model via structural equation modelling approach in Mplus (Muthen \& Muthen, 2008b, 2008a) which showed that our items loaded on to their respective latent variables satisfactorily (above .50) with an excellent model fit $\left(\chi^{2}=170.73, p=.052, d f=146, \mathrm{CFI}=.99, \mathrm{RMSEA}=.023, \mathrm{SRMR}=.041\right)$.

Hypothesis testing. We report the descriptive statistics and zero-order correlations between our variables in the model in Table 2. Means of all our variables except intergroup contact and perspective-taking were above the scale midpoint (4) and all our variables correlated in the expected direction except intergroup trust and in-group oriented collective action. Given its small magnitude, it is highly likely that this is a spurious association.

\section{[Table 2]}

Our model (Figure 2) explained 32\% and $17 \%$ of variance in endorsement of social change attempts by the disadvantaged Hungarian out-group and Romanian in-group collective action, $17 \%$ of the variance in intergroup trust, $24 \%$ of the variance in perspectivetaking, and $14 \%$ of the variance in intergroup anxiety, respectively. 
Unlike in Study 1, intergroup contact was not associated with endorsement of the social change motivations by the disadvantaged Hungarian out-group directly. It only had an indirect positive effect on endorsement of social change attempts via increased intergroup trust $(\mathrm{PE}=.11,99 \%$ CIs $[.001, .276])$, increased perspective-taking $(\mathrm{PE}=.12,99 \%$ CIs $[.005$, $.249)$, and via reduced anxiety $(\mathrm{PE}=.08,95 \% \mathrm{CIs}[.006, .185]$, whereas in-group identification had a negative indirect effect on endorsement of out-group's social change attempts $(\mathrm{PE}=-.07,95 \%$ CIs $[-.179,-007])$ via intergroup anxiety ${ }^{2}$.

Discussion. Overall, results supported the positive effects of contact on social change via both positive and negative affective mediators. To the extent that Romanians had more contact with the disadvantaged Hungarian out-group, they reported increased levels of intergroup trust and perspective-taking and decreased intergroup anxiety. In turn, intergroup trust and perspective-taking were positively but intergroup anxiety was negatively associated with endorsement of out-group collective action. Contrary to Study 1, however, we found evidence in favour of the positive link between in-group identification and intergroup anxiety, which, in turn, was associated with less endorsement of social change attempts by the disadvantaged out-group. In the absence of more conclusive evidence, we can only speculate that the effect of in-group identification on endorsement of out-group's social change attempts might be due to the conflictual nature of the intergroup relations between the two groups. We sought to address these issues and replicate our findings in a relatively more conflictual intergroup context in Israel.

\section{Study 3}

\section{Method}

Participants We recruited 240 (137 females, Mage $=23.29$ and $S D=5.67)$ participants on a voluntary basis at a public university in Israel. All participants were approached by a Jewish research assistant and were invited to participate in a survey on 
attitudes toward Palestinian citizens of Israel. After consenting, participants were told that the survey measures attitudes toward Palestinians' willingness to engage in activities aimed at improving their positions in the Israeli society.

Measures We used the same items and scales to measure our variables as in the previous 2 studies (contact $\alpha=.92$; in-group identification as Jew $\alpha=.89$; perspective-taking $\alpha=.81 ;$ anxiety $\alpha=.77 ;$ intergroup trust $\alpha=.80 ;$ collective action for the Jewish in-group $\alpha$ $=.79$; and endorsement of the Palestinian out-group social change attempts measured by the same three items we employed in Study 1, $\alpha=.72$ ).

\section{Results and Discussion}

Model construction. As in Studies 1 and 2, we used structural equation modelling and results showed that our model fit the data well $\left(\chi^{2}=201.76, p=.024, d f=164, \mathrm{CFI}=.98\right.$, RMSEA $=.031$, SRMR $=.039)$ with good factor loadings.

Hypothesis testing. We report the descriptive statistics and zero order correlations in Table 3. Unlike Study 1 and Study 2 intergroup contact had little variance showing that the amount of contact is considerably low.

\section{[Table 3]}

Our model in (Figure 3), which explained $42 \%$ and $22 \%$ of variance in endorsement of out-group social change attempts and in-group collective action, $14 \%$ of the variance in intergroup trust, $15 \%$ of the variance in perspective-taking, and $17 \%$ of the variance in intergroup anxiety, respectively.

[Figure 3]

Intergroup contact had a positive effect on endorsement of out-group social change attempts via trust $(\mathrm{PE}=.06,99 \%$ CIs $[.004, .186])$; perspective taking $(\mathrm{PE}=.07,99 \%$ CIs $[.013, .152])$; and intergroup anxiety $(\mathrm{PE}=.07,95 \%$ CIs $[.007, .177])$. In-group identification, on the other hand, was negatively associated with endorsement of social 
change attempts via trust $(\mathrm{PE}=-.11,99 \% \mathrm{CIs}[-.233,-.010])$; perspective taking $(\mathrm{PE}=-.07$, 95\% CIs $[-.171,-.009])$; and via anxiety $\left(\mathrm{PE}=-.05,95 \%\right.$ CIs $[-136,-.007]^{3}$.

Discussion. The findings are mostly in line with findings from Study 1 and Study 2. We replicated the positive effects of contact on attitudinal support for social change motivations by the disadvantaged outgroup via trust, perspective taking, and anxiety; more contact with the disadvantaged out-group Palestinians was associated with stronger endorsement of outgroup social change attempts via increased trust, perspective taking, and via decreased intergroup anxiety. Contrary to the earlier findings though, we found a much stronger negative effect of in-group identification with the Jewish in-group on social change benefitting the disadvantaged out-group. The more our participants identified with the Jewish in-group the less trust and perspective taking and the more anxiety they experienced. In fact, results from this study provided the fullest support for the positive effects of contact and negative effects of in-group identification on social change among the advantaged groups.

\section{General Discussion}

Positive contact improves out-group attitudes and decreases prejudice by increasing intergroup trust (Tam et al., 2009), perspective-taking (Aberson \& Mcvean, 2008), and by decreasing intergroup anxiety (Aberson \& Haag, 2007a; Islam \& Hewstone, 1993; Pettigrew \& Tropp, 2008) but it can also demotivate disadvantaged group members to engage in collective action (Dixon, Levine, Reicher, \& Durrheim, 2012). We investigated the positive effects of contact via positive and negative affective mediators on endorsement of social change motivations by the disadvantaged outgroup and in-group collective action among the advantaged. As hypothesized, more intergroup contact increased individuals' willingness to endorse out-group social change attempts but it did not decrease group members' willingness to engage in collective action to maintain their advantaged in-group's position. 
These findings build on existing research on the positive effects of contact on prejudice reduction (Brown \& Hewstone, 2005) and provide novel evidence in favour of the energizing effects of contact on social change (Reimer et al., 2017; Selvanathan et al., 2018). First, we show that intergroup contact effects on endorsement of disadvantaged groups' right to engage in action to challenge the status quo are consistently positive in three intergroup contexts. Across three studies contact with the disadvantaged group is associated with stronger endorsement of the social change attempts by the disadvantaged out-group both directly (Study1) and indirectly via trust, perspective-taking, and intergroup anxiety (Studies 1, 2, and 3). Pettigrew (2010) argues that intergroup contact could diminish advantaged groups' willingness to maintain the structural inequalities against the disadvantaged group on one hand and it could motivate the advantaged group members to recognize the legitimacy of the collective action by the disadvantaged group. Our results provide evidence in favour of the latter.

Second, we show that the role of intergroup contact in motivating advantaged group members to endorse social change attempts among the disadvantaged is not limited to increasing positive affect (Selvanathan et al., 2018). As our findings show, contact also motivates advantaged group members to support social change by decreasing intergroup anxiety.

Third, the results also show that so-called negative effects of contact on collective action (Cakal et al., 2011) do not apply, at least in our data, to advantaged groups. Contact was not associated, directly or indirectly, with decreased willingness to engage in collective action to maintain the status quo. This finding in particular sheds an important light on the intricacies of the intergroup contact and collective action. The consistent set of findings on the positive effects of intergroup contact on attitudinal support for social motivations among the disadvantage and the null effect of contact on in-group collective action among the 
advantaged implies that the association between contact and social change is more complex than it was previously suggested by the research on the sedative effects of contact (Cakal et al., 2011) on social change. Future research could explore the mechanisms that could motivate the advantaged group members to support the out-group collective action while demotivating them from group serving collective action simultaneously. Research using direct measures of these processes, i.e. collective action by the advantaged group to challenge the status quo in favour of the disadvantaged is particularly welcome.

Fourth, we replicate and extend previous research by showing that effects of intergroup anxiety on social change are not limited to engaging in solidarity-based collective action to support the disadvantaged out-group (Brylka et al., 2015). As findings from the third study show intergroup anxiety could influence social change in alternative ways. Firstly, contact with the disadvantaged out-group might have a positive effect on acknowledging the disadvantaged out-group's right to engage in collective action via reduced anxiety (Studies 2 and 3). Secondly, in-group identification could motivate the advantaged in-group members not to acknowledge the disadvantaged out-group's collective action intentions again via increased anxiety (Studies 2 and 3) in a violent conflict situation. These findings open up new avenues for research on how contact influences collective action motivations.

Fifth, an interesting finding that emerged from Study 3 is the significant negative correlation between in-group identification and intergroup contact. Research shows that the effects of contact are stronger and more salient in high-threat and high-conflict contexts (Kokkonen, Esaiasson, \& Gilljam, 2016). Earlier research also showed that through contact individuals might realize that in-group norms, customs, and values have no absolute supremacy over the out-group belief systems and this might lead one to relatively distance herself from the in-group, a process labelled as "deprovincialization" (Cakal et al., 2011; Pettigrew, 1998). Thus, in the absence of more robust data, we can only speculate that contact 
with Palestinians in a high-conflict context in Israel lead to a partial distancing from the Jewish in-group as reflected by the negative association between in-group identification and intergroup contact.

Last but not least, we also replicate and extend the existing research on the predictive power of social identification on collective action intentions (van Zomeren et al., 2008). A qualitative evaluation of the cumulative results from three studies show the impact of social identification on social change via different routes. Across three studies, identification with the advantaged in-group was negatively associated with endorsement of the social change motivations by the out-group indirectly via increased intergroup anxiety (Studies 2 and 3) and via decreased intergroup trust and perspective taking (Study 3). As for the in-group oriented collective action, in Study 1, a relatively low and non-violent conflict intergroup context, ingroup identification is associated with in-group oriented collective action intentions only directly. In Study 2 and Study 3, however, stronger identification with the advantaged ingroup was positively associated with the in-group collective action both directly (Studies 2 and 3), and indirectly via anxiety (Study 2), and via trust, perspective taking, and anxiety (Study 3). Findings from Study 3 suggest that in-group identification might also motivate collective action via an out-group oriented process, such as increased intergroup anxiety or decreased inter-group trust and perspective taking. Although preliminary, these findings call for future research to investigate the alternative roles that in-group identification might have in social change. Stronger identification with one's in-group might predict decreased support for the collective action by the disadvantaged out-group. Alternatively, It might also predict reactionary collective action to maintain the status quo.

Finally, we acknowledge, that there are several discrepancies between the findings we report here (Study 1) and previous research. First, inconsistent with earlier research, intergroup anxiety did not mediate the effects of contact and in-group identification on our 
out-group variables in Study 1. Based on findings from Cakal, Hewstone, Guler, and Heath (2016), which showed that intergroup contact negatively predicted perceived threats, which, in turn, were positively associated with increased willingness to engage in in-group collective action, it can be hypothesized that intergroup anxiety as a dimension of threat would predict collective action tendencies. We attribute this inconsistency to several differences between our set of studies and Cakal et al.'s (2016) findings. For instance, we did not measure the specific dimensions of threats vis-à-vis intergroup anxiety. Secondly, our first study was conducted in a relatively non-violent context. This would mean that anxiety as a perception of threat is not relevant to motivations to engage on collective action. Research shows that in relatively non-violent lower-threat contexts, individuals have comparatively positive attitudes toward the members of the out-group and it is difficult for them to become less threatened (Hodson, 2011; Kokkonen et al., 2016). Similarly, conflict-ridden and violent contexts could make the in-group identity more salient (Schmid \& Muldoon, 2015) and a more salient identity could negatively predict support for out-group collective action and increase willingness to engage in collective action. An evaluation of the three contexts, a non-violent, Cyprus, low/past violence, Romania, and violent, Israel, shows that as the level and proximity of the violence increases intergroup anxiety becomes more relevant to support outgroup's social change attempts and in-group collective action. The increasingly negative association between in-group identification and trust and perspective taking, on one hand, and positive associations between identification and anxiety in Studies 2 and 3 further corroborate this point.

Although promising, the findings we report should be interpreted with caution. First, we acknowledge that our measures are less than ideal in terms of measuring direct support for the collective action by the disadvantaged outgroup and this reflects in the evidence we provide for out hypotheses. We are aware that agreeing with the measures of attitudinal 
support for collective action by the disadvantage may not amount to actual support for social change. In fact, endorsing outgroup's right to challenge status quo might not even lead to acknowledging the structural disadvantages that the outgroup faces or trigger genuine motivation to change these disadvantages on behalf of the disadvantaged. However, we also think that social change is a multifaceted process that can take many forms and may unfold at different pace in different contexts (de la Sablonnière, 2017) . In conflictual settings such as contexts where we conducted our research social change may be slow paced and it might be unrealistic to expect the advantaged group members to openly support out-group collective action due to the intensity and recency of the conflict. Thus, we remain firm in our belief that it is still important to understand the processes that lead to attitudinal change hoping that this change would trigger more direct action.

In similar vein, we focused on intimate contact with friends. This might introduce two types of bias to our findings. Firstly, our contact measure does not measure the actual number of friends. Having one or ten friends might not actually make any difference. Secondly, previous research shows that intimate contact (Herek \& Capitanio, 1996) during which parties disclose private details is more influential than ordinary contact. Taken together, these might inflate the effects of contact on our mediating variables. In all our contexts, however, the intergroup divide is wide and contact opportunities are rare. Thus, it makes sense to assume that if there is any contact at all it is very likely to take place between friends.

Second, all our studies are based on cross-sectional data. To address this issue, we tested alternative models and compared our findings to results from previous experimental and longitudinal research. Yet, claims of causality between our variables require further confirmation.

Third, we employed student data in Studies 2 and 3. Past research has shown that findings from studies using students as research participants show variability and therefore may not be 
reliable (Peterson \& Merunka, 2014). It might be the case that our findings are limited by students' experiences that reflect the current political climate in the respective campuses. However, both studies were conducted in contexts with a history of conflict with occasional concentration of the out-group (see the comparatively lower levels of contact in these studies). Moreover, given the level of conflict in these contexts recruitment of adults from the general population is difficult. Fourth, we operationalized our outcome variables as attitudes and intentions. Conducting research on collective action in conflictual settings is perceived as suspicious and even inflammatory. Given that we focus on contested issues, questions on political attitudes, and mobilization including behavioural measures are very likely to have consequences both for the participants and the researchers (Cohen \& Arieli, 2011; Goodhand, 2000).

Substantial amount of research on reasoned behaviour and planned action (Ajzen, 1991; Ajzen \& Fishbein, 1980) shows that attitudes and intentions are two stronger antecedents of behaviour. Attitudes predict intentions, which in turn, predict actual behaviour. In other words, individuals form intentions to engage on the basis of their attitudes toward that behaviour. The more positive attitudes they have the stronger their intentions. Intentions are expressed motivations to perform that particular behaviour. In fact, in a meta-analysis of 96 datasets( $\mathrm{N}=22,594)$ attitudes and intentions emerged as the strongest antecedents of behaviour even after controlling for past behaviour and perceived behavioural control (Albarracin, Johnson, Fishbein, \& Mullerleile, 2001). Given the conflictual and politically sensitive nature of the intergroup relations across all three contexts attitudes and intentions provide an optimal approximation of the actual behaviour without incitement. This, we believe, provides additional confidence in our findings.

\section{Conclusion}


Research on how intergroup contact influences social change has predominantly focussed on sedative effects of intergroup contact among the disadvantaged groups. As our findings suggest, however, contact effects do not operate as a single-group single-direction process. Social psychological research needs to move away from this narrow approach towards a more inclusive research agenda. Research exploring how and when intergroup contact motivates advantaged groups to engage in collective action on behalf of the disadvantaged out-group, i.e. out-group-oriented collective action, is particularly welcome. Similarly, researchers should move beyond the conventional western student samples toward more conflict-ridden contexts and non-student samples. This would broaden our understanding of social change in terms of contextual and individual-level variables.

\footnotetext{
${ }^{1}$ We tested two theoretically relevant alternative models as well as a moderation test to investigate the combined effect of contact and identification on our outcome variables. Firstly, intergroup contact and in-group identification could predict perspective-taking and perspective-taking, in turn, could predict endorsement of outgroup collective action and in-group collective action via intergroup anxiety and intergroup trust in a serial mediation model. ('Alternative Model 1'). Secondly, stronger in-group identification, and anxiety as a dimension of perceived threat could predict contact and contact, in turn, could predict our outcome variables ('Alternative Model 2). We used the chi-squared test (Satorra \& Bentler, 2010) to test these alternative models, which fit the data worse than our theoretical model ("Alternative Model 1": $\chi^{2}=206.55, p=.014, d f=168, \mathrm{CFI}$ $=.98, \mathrm{RMSEA}=.028, \mathrm{SRMR}=.039 ; \Delta \chi^{2}(4)=18.60, p<.001 ;$ “Alternative Model $2 ": \chi^{2}=307.665, p=.000, d f$ $\left.=172, \mathrm{CFI}=.96, \mathrm{RMSEA}=.048, \mathrm{SRMR}=.079 ; \Delta \chi^{2}(8)=108.80, p<.001\right)$. We rejected both models as they fit the data worse than our hypothesized model. None of the interaction effects were significant so we do not report these.

${ }^{2}$ In line with Study 1, we tested the Alternative Model 1' Alternative model ("Alternative Model 1" $\chi^{2}=218.92$, $p=.000, d f=168, \mathrm{CFI}=.96, \mathrm{RMSEA}=.048, \mathrm{SRMR}=.094 ; \Delta \chi^{2}(4)=56.97, p<.000$; "Alternative Model 2" did not converge so we rejected both models. As in Study 1 we tested the interactive effects of contact and identification on our outcome variables to find that there were no significant interaction effects.

3 The same alternative models were tested for Study 3. ("Alternative Model 1" $\chi^{2}=212.67, p=.010, d f=168$, $\mathrm{CFI}=.98, \mathrm{RMSEA}=.033, \mathrm{SRMR}=.052 ; \Delta \chi^{2}(4)=9.91 .97, p<.05 ;$ “Alternative Model 2": $\chi^{2}=290.11, p$ $\left.=.000, d f=172, \mathrm{CFI}=.95, \mathrm{RMSEA}=.053, \mathrm{SRMR}=.116 ; \Delta \chi^{2}(8)=71.99, p<.001\right)$. Both models were rejected. Again, tests did not reveal any significant interaction effects of contact and identification on our outcome variables.
} 


\section{References}

Aberson, C. L., \& Haag, S. C. (2007a). Contact, perspective taking, and anxiety as predictors of stereotype endorsement, explicit attitudes, and implicit attitudes. Group Processes and Intergroup Relations, 10, 179-201. https://doi.org/10.1177/1368430207074726

Aberson, C. L., \& Haag, S. C. (2007b). Contact, Perspective Taking, and Anxiety as Predictors of Stereotype Endorsement, Explicit Attitudes, and Implicit Attitudes. Group Processes \& Intergroup Relations, 10(2), 179-201. https://doi.org/10.1177/1368430207074726

Aberson, C. L., \& Mcvean, A. D. W. (2008). Contact and Anxiety as Predictors of Bias Toward the Homeless. Journal of Applied Social Psychology, 38, 3009-3035. https://doi.org/10.1111/j.1559-1816.2008.00423.x

Adalah. (2011). The Inequality Report: The Palestinian Arab Minority in Israel.

Ajzen, I. (1991). The theory of planned behavior. Organizational Behavior and Human Decision Processes, 50, 179-211.

Ajzen, I., \& Fishbein, M. (1980). Understanding attitudes and predicting social behavior. Englewood Cliffs, NJ: Prentice-Hall.

Albarracin, D., Johnson, B. T., Fishbein, M., \& Mullerleile, P. A. (2001). Theories of Reasoned Action and Planned Behavior as Models of Condom Use: A Meta-Analysis Dolores. Psychological Bulletin, 127, 142-161. https://doi.org/http://dx.doi.org/10.1037/0033-2909.127.1.142

Allport, G. W. (1954). The nature of prejudice. Garden City, NY: Doubleday.

Balliet, D., \& Van Lange, P. A. M. (2013). Trust, conflict, and cooperation: a meta-analysis. 
Psychological Bulletin, 139(5), 1090-1112. https://doi.org/10.1037/a0030939

Batson, C. D. (2011). Altrusim in Humans. New York, NY: Oxford University Press.

Batson, C. D., Chang, J., Orr, R., \& Rowland, J. (2002). Empathy, attitudes, and action: Can feeling for a member of a stigmatized group motivate one to help the group? Personality and Social Psychology Bulletin, 28, 1656-1666.

https://doi.org/10.1177/014616702237647

Batson, C. D., Sager, K., Garst, E., Kang, M., Rubchinsky, K., \& Dawson, K. (1997). Is empathy-induced helping due to self-other merging ? Journal of Personality and Social Psychology, 73, 495-509.

Bentler, P. (2007). On tests and indices for evaluating structural models. Personality and Individual Differences, 42, 825-829. https://doi.org/10.1016/j.paid.2006.09.024

Binder, J., Zagefka, H., Brown, R., Funke, F., Mummendey, A., Maquil, A., ... Leyens, J. P. (2009). Does contact reduce prejudice or does prejudice reduce contact? A longitudinal test of the contact hypothesis among majority and minority groups in three european countries. Journal of Personality and Social Psychology, 96, 843-856.

https://doi.org/10.1037/a0013470

Brewer, M. B. (2008). Deprovincialization: social identity complexity and out-group acceptance. In U. Wagner, L. R. Tropp, G. Finchilescu, \& C. Tredoux (Eds.), Emerging research directions for improving intergroup relations: Building on the legacy of Thomas F. Pettigrew (pp. 160-176). Oxford, England.

Brown, R., Cehajic, S., \& Castano, E. (2008). Forgive and Forget? Antecedents and Consequences of Intergroup Forgiveness in Bosnia and Herzegovina. Political Psychology, 29, 351-367. https://doi.org/10.1111/j.1467-9221.2008.00634.x 
Brown, R., \& Hewstone, M. (2005). An integrative theory of intergroup contact. In M. P. Zanna (Ed.), Advances in Experimental Social Psychology (Vol. 37, pp. 255-342). San Diego, CA: Academic Press. https://doi.org/10.1016/S0065-2601(05)37005-5

Brown, Rupert. (2000). Social identity theory: Past achievements , current problems and future challenges. European Journal of Social Psychology, 30, 634-667.

Brylka, A., Mähönen, T. A., Schellhaas, F. M. H., \& Jasinskaja-lahti, I. (2015). From Cultural Discordance to Support for Collective Action : The Roles of Intergroup Anxiety , Trust, and Group Status. Journal of Cross-Cultural Psychology, 46, 897-915. https://doi.org/10.1177/0022022115589118

Butz, D. A., \& Plant, E. A. (2006). Perceiving outgroup members as unresponsive: Implications for approach-related emotions, intentions, and behavior. Journal of Personality and Social Psychology, 91, 1066-1079. https://doi.org/10.1037/00223514.91.6.1066

Cakal, H. (2012). Intergroup relations in northern Cyprus: Turkish Cypriot perspectives. Department of Psychology, Working Paper No: 2012-1, University of Oxford. Oxford, England.

Cakal, H., Eller, A., Sirlopú, D., \& Perez, A. (2016). Intergroup relations in Latin America: Intergroup contact, common ingroup identity and activism among Indigenous groups in Mexico and Chile. Journal of Social Issues, Special Is, xxx. https://doi.org/xxx

Cakal, H., Hewstone, M., Guler, M., \& Heath, A. (2016). Predicting support for collective action in the conflict between Turks and Kurds: Perceived threat as a mediator of intergroup contact and social identity. Group Processes \& Intergroup Relations, 19, 732-752. https://doi.org/10.1177/1368430216641303 
Çakal, H., Hewstone, M., Güler, M., \& Heath, A. (2016). Predicting support for collective action in the conflict between Turks and Kurds: Perceived threats as a mediator of intergroup contact and social identity. Group Processes and Intergroup Relations, 19(6). https://doi.org/10.1177/1368430216641303

Cakal, H., Hewstone, M., Schwar, G., \& Heath, A. (2011). An investigation of the social identity model of collective action and the 'sedative' effect of intergroup contact among Black and White students in South Africa. British Journal of Social Psychology, 50, 606-627. https://doi.org/10.1111/j.2044-8309.2011.02075.x

Cehajic, S., Brown, R., \& Castano, E. (2008). Forgive and Forget? Antecedents and Consequences of Intergroup Forgiveness in Bosnia and Herzegovina. Political Psychology, 29, 351-367.

Cohen, N., \& Arieli, T. (2011). Field research in conflict environments: Methodological challenges and snowball sampling. Journal of Peace Research, 48, 423-435. https://doi.org/10.1177/0022343311405698

Costello, K., \& Hodson, G. (2011). Social dominance-based threat reactions to immigrants in need of assistance. European Journal of Social Psychology, 41, 220-231. https://doi.org/10.1002/ejsp.769

Culic, I., Horvath, I. L., \& Marius-Magyari, N. L. (1998). Romani si maghiari in tranzitia postcomunista [Romanians and Hungarians in post-communist transition]. Cluj.

Davis, M. (2004). Empathy: Negotiating the border between self and other. In L. Z. Tiedens \& C. W. Leach (Eds.), The social life of emotions (pp. 19-42). New York, NY: Cambridge University Press.

de la Sablonnière, R. (2017). Toward a psychology of social change: A typology of social 
change. Frontiers in Psychology, 8, 1-20. https://doi.org/10.3389/fpsyg.2017.00397

Dixon, J., Cakal, H., Khan, W., Osmany, M., Majumdar, S., \& Hassan, M. (2017). Contact, Political Solidarity and Collective Action: An Indian Case Study of Relations between Historically Disadvantaged Communities. Journal of Community \& Applied Social Psychology, 27, 83-95. https://doi.org/10.1002/casp.2296

Dixon, J., Durrheim, K., Tredoux, C. G., Tropp, L. R., Clack, B., Eaton, L., \& Quayle, M. (2010). Challenging the stubborn core of opposition to equality: Racial contact and policy attitudes. Political Psychology, 31, 831-855. https://doi.org/10.1111/j.14679221.2010.00792.x

Dixon, J., Levine, M., Reicher, S., \& Durrheim, K. (2012). Beyond prejudice: Are negative evaluations the problem and is getting us to like one another more the solution? Behavioral and Brain Sciences, 35, 411-425. https://doi.org/10.1017/S0140525X11002214

Dixon, J., Tropp, L. R., Durrheim, K., \& Tredoux, C. (2010). "Let them eat harmony”: Prejudice-reduction strategies and attitudes of historically disadvantaged groups. Current Directions in Psychological Science, 19, 76-80. https://doi.org/10.1177/0963721410363366

Fingerhut, A. W. (2011). Straight Allies : What Predicts Heterosexuals' Alliance With the LGBT Community? Journal of Applied Social Psychology, 2230-2248. https://doi.org/10.1111/j.1559-1816.2011.00807.x

Galinsky, A. D., Ku, G., \& Wang, C. S. (2005). Perspective-Taking and self-other overlap: Fostering social bonds and facilitating social coordination. Group Processes \& Intergroup Relations, 8, 109-124. https://doi.org/10.1177/1368430205051060 
Galinsky, A. D., \& Moskowitz, G. B. (2000). Perspective-taking: Decreasing stereotype expression, stereotype accessibility, and in-group favoritism. Journal of Personality and Social Psychology, 78, 708-724. https://doi.org/10.1037//0022-3514.78.4.708

Goodhand, J. (2000). Research in conflict zones: ethics and accountability. Forced Migration Review, 8, 12-15.

Haferkamp, H., \& Smelser, N. J. (1992). Social Change and Modernity. Social Change. Berkeley: University of California Press.

Hameiri, B., \& Nadler, A. (2017). Looking Backward to Move Forward. Personality and Social Psychology Bulletin, 43, 555-569. https://doi.org/10.1177/0146167216689064

Hatay, M. (2007). Is the Turkish Cypriot population shrinking? An overview of the ethnodemography of Cyprus in the light of the preliminary results of the 2006 Turkish-Cypriot census. Nicosia.

Herek, G., \& Capitanio, J. P. (1996). "Some of My Best Friends": Intergroup Contact, Concealable Stigma, and Heterosexuals’ Attitudes Toward Gay Men and Lesbians. Personality \& Social Psychology Bulletin, 22, 412-424. https://doi.org/https://doi.org/10.1177/0146167296224007

Hodson, G. (2011). Do Ideologically Intolerant People Benefit From Intergroup Contact? Current Directions in Psychological Science, 20, 154-159. https://doi.org/10.1177/0963721411409025

Hu, L., \& Bentler, P. M. (1999). Cutoff criteria for fit indices in covariance structure analysis: Conventional criteria versus new alternatives. Structural Equation Modeling, 6, 1-55. https://doi.org/10.1080/10705519909540118 
Islam, M. R., \& Hewstone, M. (1993). Dimensions of Contact as Predictors of Intergroup Anxiety, Perceived Out-Group Variability, and Out-Group Attitude: An Integrative Model. Personality and Social Psychology Bulletin, 19, 700-710. https://doi.org/10.1177/0146167293196005

Kline, R. B. (2011). Principles and practice of structural equation modelling (3rd ed.). New York, NY: The Guildford Press.

Kokkonen, A., Esaiasson, P., \& Gilljam, M. (2016). Contact in context: does intergroup contact function (better) in high-threat contexts? Ethnic and Racial Studies, 39, 634652. https://doi.org/10.1080/01419870.2015.1080378

Kramer, R. M., \& Carnevale, P. J. (2001). Trust and intergroup nego- tiation. In Rupert Brown \& S. L. Gaertner (Eds.), Blackwell handbook of social psychology: Intergroup processes (pp. 431-450). Malden, MA: Blackwell.

Leach, C. W., Iyer, A., \& Pedersen, A. (2007). Angry opposition to government redress: When the structurally advantaged perceive themselves as relatively deprived. The British Journal of Social Psychology, 46, 191-204. https://doi.org/10.1348/014466606X99360

Lewicki, R. J., McAllister, D. J., \& Bies, R. J. (1998). Trust and distrust: New relationships and realities. Academy of Management Review, 23, 438-458. https://doi.org/10.2307/259288

Lipcsey, I., Gherman, S., \& Severin, A. (2006). Romania and Transylvania in the 20th Century. Budapest: Corvinius.

Loizides, N. (2011). Contested migration and settler politics in Cyprus. Political Geography, 30, 391-401. https://doi.org/10.1016/j.polgeo.2011.08.004 
Lowery, B. S., Unzueta, M. M., Knowles, E. D., \& Goff, P. A. (2006). Concern for the ingroup and opposition to affirmative action. Journal of Personality and Social Psychology, 90, 961-974. https://doi.org/10.1037/0022-3514.90.6.961

Luhtanen, R., \& Crocker, J. (1992). A collective self-esteem scale: Self-evaluation of one's social identity. Personality and Social Psychology Bulletin, 18, 302-318. https://doi.org/10.1177/0146167292183006

Mallett, R. K., Huntsinger, J. R., Sinclair, S., \& Swim, J. K. (2008). Seeing through their eyes: When majority group members take collective action on behalf of an outgroup. Group Processes and Intergroup Relations, 11, 451-470. https://doi.org/10.1177/1368430208095400

Martinez, C. (2000). Intención de contacto, ansiedad y actitud en la relación con exiguous [Intention of contact, anxiety, and attitude in relationships with outgroups]. Revista de Psicología Social, 15, 31-44.

Muthen, L. K., \& Muthen, B. O. (2008a). Mplus software package. Los Angeles, CA, USA: Muthen \& Muthen.

Muthen, L. K., \& Muthen, B. O. (2008b). Mplus user's guide (5th ed.). Los Angeles, CA: Muthen \& Muthen.

Navaro-Yashin, Y. (2006). De-ethnicisizing the ethnography of Cyprus: Political and social conflict between Turkish Cypriots and settlers from Turkey. In Y. Papadakis, N. Peristianis, \& G. Welz (Eds.), Divided Cyprus: Modernity, history, and an island in conflict (pp. 84-99). Bloomington, IN.

O’Brien, L. T., Garcia, D., Crandall, C. S., \& Kordys, J. (2010). White Americans' opposition to affirmative action: Group interest and the harm to beneficiaries objection. 
British Journal of Social Psychology, 49, 895-903.

https://doi.org/10.1348/014466610X518062

Peterson, R. A., \& Merunka, D. R. (2014). Convenience samples of college students and research reproducibility. Journal of Business Research, 67, 1035-1041. https://doi.org/10.1016/j.jbusres.2013.08.010

Pettigrew, T. F. (1998). Intergroup contact theory. Annual Review of Psychology, 49, 65-85. https://doi.org/10.1146/annurev.psych.49.1.65

Pettigrew, T. F. (2010). Commentary: South African contributions to the study of intergroup relations. Journal of Social Issues, 66, 417-430. https://doi.org/10.1111/j.15404560.2010.01653.x

Pettigrew, T. F., \& Tropp, L. R. (2008). How does intergroup contact reduce prejudice? Meta-analytic tests of three mediators. European Journal of Social Psychology, 38, 922934. https://doi.org/10.1002/ejsp

Psaltis, C., Cakal, H., Kuşçu, I., \& Loizides, N. (2019). Internally Displaced Persons and theExclusion amid Inclusion Dilemma in the Cyprus Peace Process. International Political Science Review, 1-16. https://doi.org/10.1177/0192512119872057

Reimer, N. K., Becker, J. C., Benz, A., Christ, O., Dhont, K., Klocke, U., ... Hewstone, M. (2017). Intergroup Contact and Social Change: Implications of Negative and Positive Contact for Collective Action in Advantaged and Disadvantaged Groups. Personality and Social Psychology Bulletin, 43, 121-136. https://doi.org/10.1177/0146167216676478

Renfro, C. L., Duran, A., Stephan, W. G., \& Clason, D. L. (2006). The Role of Threat in Attitudes Toward Affirmative Action and Its Beneficiaries. Journal of Applied Social 
Psychology, 36, 41-74. https://doi.org/10.1111/j.0021-9029.2006.00003.x

Saguy, T., Tausch, N., Dovidio, J. F., \& Pratto, F. (2009). The irony of harmony.

Psychological Science, 20, 114-121. https://doi.org/10.1111/j.1467-9280.2008.02261.x.

Satorra, A., \& Bentler, P. M. (2010). Ensuring positiveness of the scaled difference chisquare test statistic. Psychometrika, 75, 243-248. https://doi.org/10.1007/s11336-0099135-y.

Schmid, K., \& Muldoon, O. T. (2015). Perceived Threat, Social Identification, and Psychological Well-Being: The Effects of Political Conflict Exposure. Political Psychology, 36, 75-92. https://doi.org/10.1111/pops.12073

Selvanathan, H. P., Techakesari, P., Tropp, L. R., \& Barlow, F. K. (2018). Whites for racial justice: How contact with Black Americans predicts support for collective action among White Americans. Group Processes and Intergroup Relations, 21, 893-912. https://doi.org/10.1177/1368430217690908

Sengupta, N. K., \& Sibley, C. G. (2013). Perpetuating one's own disadvantage: intergroup contact enables the ideological legitimation of inequality. Personality \& Social Psychology Bulletin, 39, 1391-1403. https://doi.org/10.1177/0146167213497593

Shih, M., Wang, E., Trahan Bucher, A., \& Stotzer, R. (2009). Perspective taking: Reducing prejudice towards general outgroups and specific individuals. Group Processes \& Intergroup Relations, 12, 565-577. https://doi.org/10.1177/1368430209337463

Smith, H. J., Cronin, T., \& Kessler, T. (2008). Anger, fear, or sadness: Faculty members' emotional reactions to collective pay disadvantage. Political Psychology, 29, 221-246. https://doi.org/10.1111/j.1467-9221.2008.00624.x 
Statistics, C. B. of. (2016). Statistical Abstract of Israel. Retrieved April 4, 2019, from https://www.cbs.gov.il/he/pages/default.aspx

Stephan, W. G. (2014). Intergroup Anxiety: Theory, Research, and Practice. Personality and Social Psychology Review, 18, 239-255. https://doi.org/10.1177/1088868314530518

Stephan, W. G., \& Stephan, C. (1985). Intergroup anxiety. Journal of Social Issues, 41, 157175. https://doi.org/10.1111/j.1540-4560.1985.tb01134.x

Swart, H., Hewstone, M., Christ, O., \& Voci, A. (2011). Affective mediators of intergroup contact: a three-wave longitudinal study in South Africa. Journal of Personality and Social Psychology, 101, 1221-1238. https://doi.org/10.1037/a0024450

Tam, T., Hewstone, M., Kenworthy, J., \& Cairns, E. (2009). Intergroup trust in Northern Ireland. Personality and Social Psychology Bulletin, 35, 45-59. https://doi.org/10.1177/0146167208325004

Tanis, M., \& Postmes, T. O. M. (2005). Short Communication A social identity approach to trust : Interpersonal perception, group membership and trusting behaviour. European Journal of Social Psychology, 35, 413-424. https://doi.org/10.1002/ejsp.256 Short

Tarrant, M., Calitri, R., \& Weston, D. (2012). Social identification structures the effects of perspective taking. Psychological Science, 23, 973-978. https://doi.org/10.1177/0956797612441221

Todd, A. R., Bodenhausen, G. V., \& Galinsky, A. D. (2012). Perspective taking combats the denial of intergroup discrimination. Journal of Experimental Social Psychology, 48, 738-745. https://doi.org/10.1016/j.jesp.2011.12.011 
Todd, A. R., Hanko, K., Galinsky, A. D., \& Mussweiler, T. (2011). When Focusing on Differences Leads to Similar Perspectives. Psychological Science, 22, 134-141. https://doi.org/10.1177/0956797610392929

Todd, A. R., \& Simpson, A. J. (2017). Perspective taking and member-to-group generalization of implicit racial attitudes : The role of target prototypicality. European Journal of Social Psychology, 47, 105-112. https://doi.org/10.1002/ejsp.2204

Van Zomeren, M., Fischer, A. H., \& Spears, R. (2007). Testing the limits of tolerance: how intergroup anxiety amplifies negative and offensive responses to out-group-initiated contact. Personality \& Social Psychology Bulletin, 33, 1686-1699. https://doi.org/10.1177/0146167207307485

van Zomeren, M., Postmes, T., \& Spears, R. (2008). Toward an integrative social identity model of collective action: A quantitative research synthesis of three sociopsychological perspectives. Psychological Bulletin, 134, 504-535. https://doi.org/10.1037/0033-2909.134.4.504

Vescio, T. K., Sechrist, G. B., \& Paolucci, M. P. (2003). Perspective taking and prejudice reduction: the mediational role of empathy arousal and situational attributions. European Journal of Social Psychology, 33, 455-472. https://doi.org/10.1002/ejsp.163 
Table 1. Descriptive statistics and correlations between the latent variables in the model (Study 1 Cyprus).

\begin{tabular}{|c|c|c|c|c|c|c|c|c|c|}
\hline Variable & $\bar{M}$ & $\mathrm{SD}$ & 1 & 2 & 3 & 4 & 5 & 6 & 7 \\
\hline 1. Inter-group Contact & 3.16 & 1.80 & & $-.09^{\mathrm{ns}}$ & $.28^{* * * *}$ & $.31^{* * * *}$ & $11^{\mathrm{ns}}$ & $.19^{* *}$ & $.12^{\mathrm{ns}}$ \\
\hline 2. In-group Identification & 5.59 & 1.81 & & & $.05^{\mathrm{ns}}$ & $-04^{\mathrm{ns}}$ & $.40^{* * *}$ & $.07^{\mathrm{ns}}$ & $.38^{* * * *}$ \\
\hline 3. Inter-group Trust & 2.80 & 1.39 & & & & $.40^{* * *}$ & $.14^{*}$ & $.30^{* * *}$ & $.04^{* * * *}$ \\
\hline 4. Perspective Taking & 4.32 & 1.76 & & & & & $-.03^{\mathrm{ns}}$ & $.32^{* * *}$ & $.01^{\mathrm{ns}}$ \\
\hline 5. Inter-group Anxiety & 4.25 & 1.63 & & & & & & $-.03^{\mathrm{ns}}$ & $.23^{*}$ \\
\hline 6. Endorsement of OG Collective Action & 4.11 & 2.05 & & & & & & & $.14^{*}$ \\
\hline 7. In-group Collective Action & 5.96 & 1.49 & & & & & & & \\
\hline
\end{tabular}

Note. Standardized coefficients are shown. Scales went from 1 (strongly disagree) to 7 (strongly agree). $* p<.05 ; * * p<.001$; 
Table 2. Descriptive statistics and correlations between the latent variables in the model (Study 2 Romania).

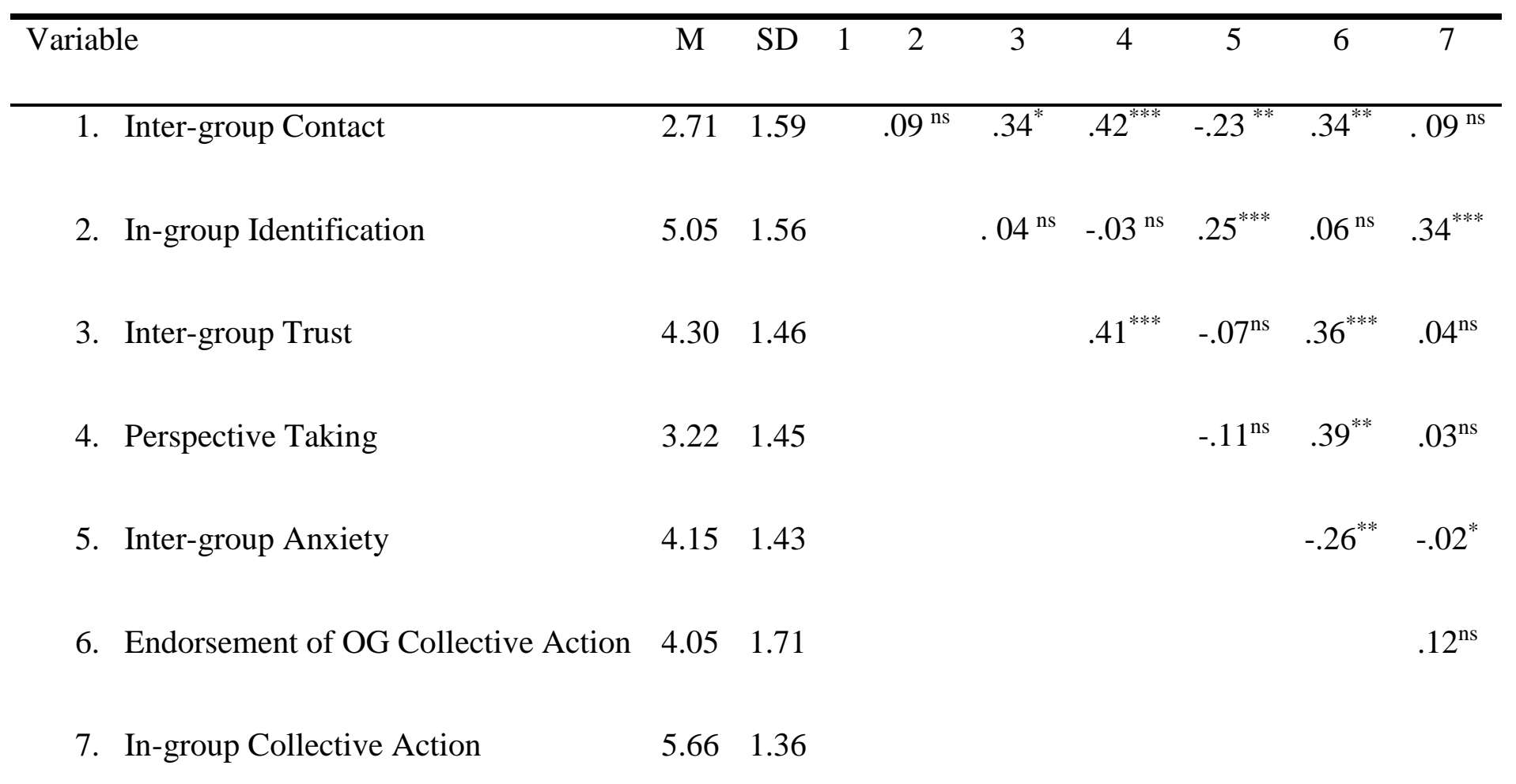

Note. Standardized coefficients are shown. Scales went from 1 (strongly disagree) to 7 (strongly agree). ${ }^{*} p<.05 ; * * p<.001$. 
Table 3. Descriptive statistics and correlations between the latent variables in the model (Study 3 Israel).

\begin{tabular}{|c|c|c|c|c|c|c|c|c|}
\hline Variable & M & $\mathrm{SD}$ & 1 & 3 & 4 & 5 & 6 & 7 \\
\hline 1. Inter-group Contact & 1.34 & .89 & $-.13^{*}$ & $.22^{*}$ & $.22^{*}$ & $-.28^{*}$ & $.19^{*}$ & $-.08^{\mathrm{ns}}$ \\
\hline 2. In-group Identification & 4.16 & 1.57 & & $-.25^{* *}$ & $-.27^{* *}$ & $26^{* *}$ & $-.22^{* *}$ & $.32^{* *}$ \\
\hline 3. Inter-group Trust & 3.87 & 1.40 & & & $.30^{* *}$ & $-.38^{* *}$ & $.39^{* *}$ & $-.31^{* *}$ \\
\hline 4. Perspective Taking & 4.44 & 1.39 & & & & $-.37^{* * *}$ & $.42^{* *}$ & $-.29^{* *}$ \\
\hline 5. Inter-group Anxiety & 3.46 & 1.44 & & & & & $-.44^{* *}$ & $.18^{* *}$ \\
\hline 6. Endorsement of OG Collective Action & 5.31 & 1.52 & & & & & & $-.21^{* *}$ \\
\hline 7. In-group Collective Action & 4.65 & 1.58 & & & & & & \\
\hline
\end{tabular}

Note. Standardized coefficients are shown. Scales went from 1 (strongly disagree) to 7 (strongly agree). ${ }^{*} p<.05 ; * * p<.001$. 
Figure Captions

Figure 1 Model showing contact and in-group identification predicting support for disadvantaged out-group collective action and in-group collective action among Turkish Cypriots ( $\mathrm{N}=336$; Study 1). Correlations between other variables in the model (intergroup contact-in-group identification, $r=-.08, p=.19$; endorsement of out-group collective action - in-group oriented collective action, $r=.14, p<.05$; Trustperspective taking $r=.41, p<.001$; Trust-anxiety $r=-.60, p<, 001$; perspective taking-anxiety $r=-.24, p<.001$;

Figure 2 Model showing contact and in-group identification predicting support for disadvantaged out-group collective action and in-group collective action among Romanians ( $\mathrm{N}=197$; Study 2). Correlations between other variables in the model Correlations between other variables in the model (intergroup contact-in-group identification, $r=.04, p=.65$; endorsement of out-group collective action - in-group oriented collective action, $r=.13, p=.12$; Trust-perspective taking $r=.38, p<.001$; Trust-anxiety $r=.07, p=.50$; perspective taking-anxiety $r=.01$, $\mathrm{p}=$ 90

Figure 3 Model showing contact and in-group identification predicting support for disadvantaged out-group collective action and in-group collective action among Israeli Jews ( $=240$; Study 3). Correlations between other variables in the model (intergroup contact-in-group identification, $r=-.15, p=.15$; endorsement of out-group collective action - in-group oriented collective action, $r=.03, p=.70$; Trustperspective taking $r=.29, p<.001$; Trust-anxiety $r=-.39, \mathrm{p}<, 001$; perspective taking-anxiety $r=-.38, \mathrm{p}<.001$; 
Figure 1:

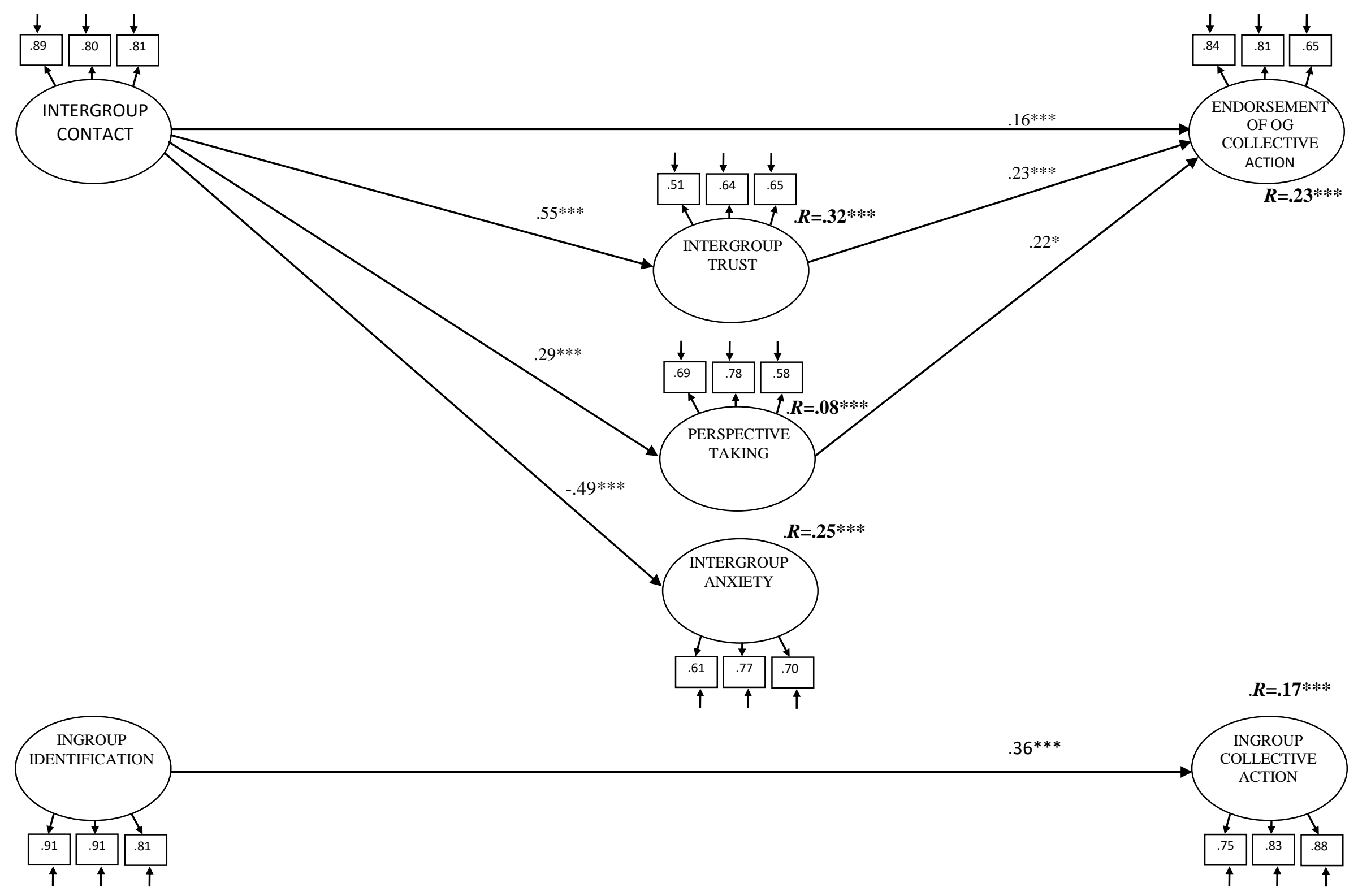


Figure 2:

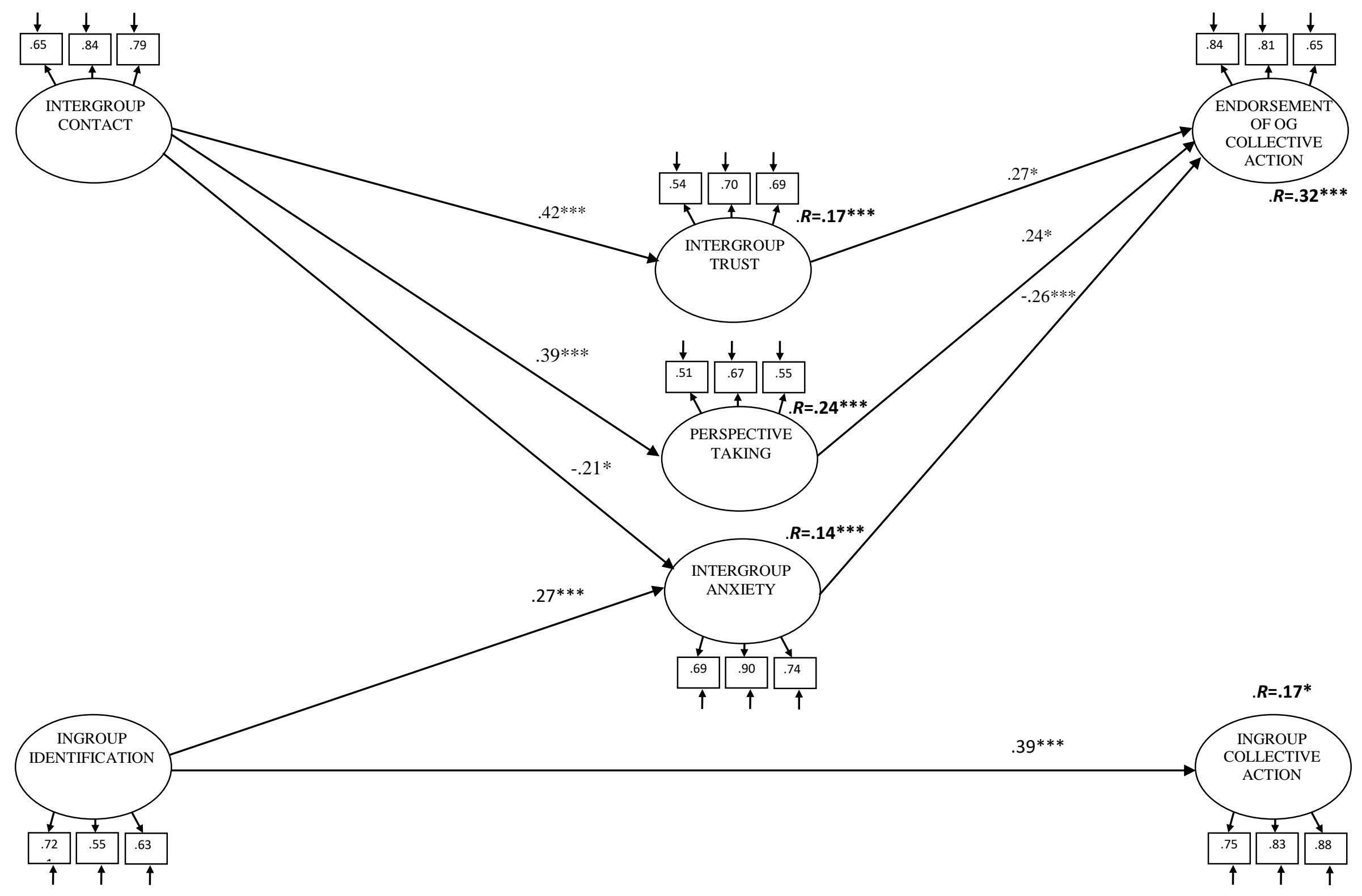


Figure 3.

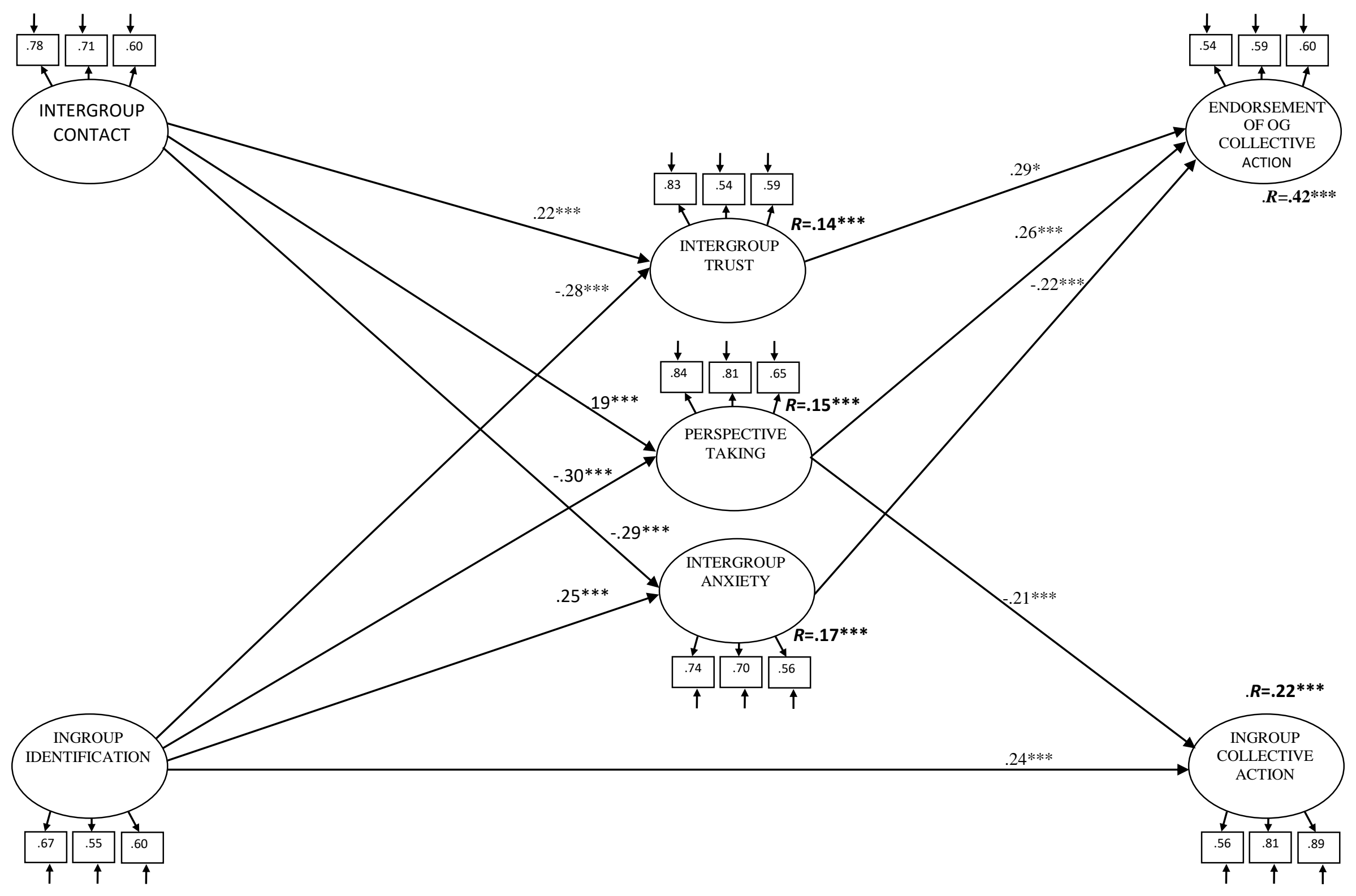


